\title{
Characterization of tumor-associated MUC1 and its glycans expressed in mucoepidermoid carcinoma
}

\author{
EISAKU ISAKA ${ }^{1}$, TAKANORI SUGIURA ${ }^{1}$, KAZUHIKO HASHIMOTO $^{2}$, KAZUTAKA KIKUTA ${ }^{3}$, \\ UKEI ANAZAWA $^{4}$, TAKESHI NOMURA ${ }^{1,5}$ and AKIHIKO KAMEYAMA ${ }^{6}$ \\ ${ }^{1}$ Department of Oral Oncology, Oral and Maxillofacial Surgery; ${ }^{2}$ Department of Pathology and \\ Laboratory Medicine, Ichikawa General Hospital, Tokyo Dental College, Ichikawa-shi, Chiba 272-8513; \\ ${ }^{3}$ Department of Musculoskeletal Oncology and Orthopaedic Surgery, Tochigi Cancer Center, Utsunomiya, \\ Tochigi 320-0834; ${ }^{4}$ Department of Orthopaedic Surgery; ${ }^{5}$ Oral Cancer Center, Tokyo Dental College, \\ Ichikawa-shi, Chiba 272-8513; ${ }^{6}$ Cellular and Molecular Biotechnology Research Institute, National Institute of \\ Advanced Industrial Science and Technology (AIST), Tsukuba, Ibaraki 305-8565, Japan
}

Received March 24, 2021; Accepted June 21, 2021

DOI: $10.3892 / 01.2021 .12963$

\begin{abstract}
Mucoepidermoid carcinoma (MEC) is one of the most frequently misdiagnosed tumors. Glycans are modulated by malignant transformation. Mucin 1 (MUC1) is a mucin whose expression is upregulated in various tumors, including MEC, and it has previously been investigated as a diagnostic and prognostic tumor marker. The present study aimed to reveal the differences in the mucin glycans between MEC and normal salivary glands (NSGs) to discover novel diagnostic markers. Soluble fractions of salivary gland homogenate prepared from three MEC salivary glands and 7 NSGs were evaluated. Mucins in MEC and NSGs were separated using supported molecular matrix electrophoresis, and stained with Alcian blue and monoclonal antibodies. The glycans of the separated mucins were analyzed by mass spectrometry. MUC1 was found in MEC but not in NSGs, and almost all glycans of MUC1 in MEC were sialylated, whereas the glycans of mucins in NSGs were less sialylated. The core 2 type glycans,
\end{abstract}

Correspondence to: Dr Akihiko Kameyama, Cellular and Molecular Biotechnology Research Institute, National Institute of Advanced Industrial Science and Technology (AIST), 1-1-1 Higashi, Tsukuba, Ibaraki 305-8565, Japan

E-mail: aki-kameyama@aist.go.jp

Abbreviations: 2,5-DHB, 2,5-dihydroxybezoic acid; FNAC, fine-needle aspiration cytology; HABP, hyaluronic acid binding protein; MEC, mucoepidermoid carcinoma; MS, mass spectrometry; NSG, normal salivary gland; PGM, porcine gastric mucin; PVA, poly (vinyl alcohol); PVP, polyvinylpyrrolidone; QIT, quadrupole ion trap; SMME, supported molecular matrix electrophoresis; STn, sialyl Tn; TOF, time-of-flight; VNTR, variable number of tandem repeat

Key words: salivary gland, mucoepidermoid carcinoma, mucin, $O$-glycan, mucin 1
$(\mathrm{Hex})_{2}(\mathrm{HexNAc})_{2}(\mathrm{NeuAc})_{1}$ and $(\mathrm{Hex})_{2}(\mathrm{HexNAc})_{2}(\mathrm{NeuAc})_{2}$, were found to be significantly abundant glycans of MUC1 in MEC. MEC markedly produced MUC1 modified with sialylated core 2 glycans. These data were obtained from the soluble fractions of salivary gland homogenates. These findings provide a basis for the utilization of MUC1 as a serum diagnostic marker for the preoperative diagnosis of MEC.

\section{Introduction}

Salivary gland carcinomas are rare tumors that account for about 3 to $6 \%$ of head and neck cancers. The WHO classified salivary gland tumors into over 20 different tissue types in 2017 (1). Mucoepidermoid carcinoma (MEC) is the most common malignant salivary tumor and constitutes approximately $30 \%$ of all malignant tumors of the salivary gland (2). Surgery is the only definitive treatment for all salivary gland tumors, including MEC. The types and scopes of surgery vary greatly depending on the stage and grade of the tumor $(3,4)$. Preoperative diagnosis helps to guide operative strategy and clinical management $(5,6)$. A previous study reported that high-grade MEC may have lymph node metastasis, and when high-grade MEC is diagnosed before surgery, neck dissection is also considered (7).

In addition to genetic changes, epigenetic changes also play an important role in neoplastic transformation (8). The glycosylation of proteins also changes with epigenetic alterations. Glycan alterations are common features of tumor cells $(9,10)$ and have been aggressively studied as cancer biomarkers and functional molecules involved in malignant behaviors, including metastasis and cancer cell proliferation. Mucins are hyperglycosylated proteins in which the glycans attach to Ser/Thr residues in the variable number of tandem repeat (VNTR) region of the mucins. A serum tumor marker, CA19-9, is a glycan antigen found on MUC1, and is involved in the promotion of metastasis and the dissemination of cancer cells (11). MUC1, modified with certain glycans (tumor-associated MUC1) such as sialyl 
Lewis a, sialyl Lewis $\mathrm{X}$, and sialyl Tn, is known as a marker of various tumors (12-15). Tumor-associated MUC1 is widely distributed in both primary and metastatic tumors, including cancer stem cells, and has been widely considered a target for many diagnostic and immunological therapeutic approaches. Based on certain criteria, such as therapeutic function, immunogenicity, and cancer cell specificity, MUC1 was listed by the National Cancer Institute pilot project to prioritize cancer antigens as the second most promising target in cancer research from a list of 75 tumor-associated antigens (16). MUC1 expression has also been reported to be associated with the histological grade of MEC $(17,18)$. In this study, mucins and their glycans expressed in MEC were analyzed and compared with normal salivary glands (NSGs). Mucins are extensively glycosylated proteins with high molecular weights of over 1,000 kDa and are difficult to analyzed using conventional proteomic techniques. In the present study, mucins were analyzed using supported molecular matrix electrophoresis (SMME), a membrane electrophoresis method, that was previously developed to characterize mucins (19). The mucins were stained on the SMME membranes using specific antibodies (20). Furthermore, we analyzed the glycans attached to the mucins by mass spectrometry (MS) and revealed that MEC specifically produced MUC1 with core 2 type glycans modified with sialic acid.

\section{Materials and methods}

Case selection. All cases were diagnosed and classified by experienced oral pathologists. The pathological classification was described based on TNM Classification of Malignant Tumors (8th edition) by the Union for International Cancer Control (UICC) (21). Salivary glands were surgically removed from patients with a diagnosis of MEC and other salivary gland tumors. Surplus tissues that did not contain malignant cells were used as samples of NSGs. In this study, MEC samples and NSG samples were obtained from different patients, respectively. The tissues were cut to a predetermined size $(2 \times 2 \mathrm{~mm})$ and then immediately stored in a freezer at $-80^{\circ} \mathrm{C}$ until further use. This research was approved by the Tokyo Dental College Ichikawa General Hospital Ethics Review Committee (I16-74) and the AIST Committee on Bioethics of Experiments Involving Human-derived Materials (h-213). Written informed consent was obtained for experimentation with human subjects.

Chemicals and materials. A polyvinylidene difluoride (PVDF) membrane (Immobilon-P; pore size, $0.45 \mu \mathrm{m}$ ) was purchased from EMD Millipore. Poly (vinyl alcohol) (PVA; MW, 22,000) was purchased from Wako Pure Chemical Industries. Poly (ethylene glycol) (PEG; MW: 20,000) and polyvinylpyrrolidone (PVP; MW: 20,000) were purchased from Nacalai Tesque Inc. Porcine gastric mucin (PGM) (type III, partially purified) and Alcian blue 8GX were purchased from Sigma-Aldrich; Merck KGaA. Anti-sialyl MUC1 monoclonal antibody (MY.1E12) was provided by Dr T. Irimura (Juntendo University, Japan) $(22,23)$. Hyaluronic acid binding protein (HABP) was obtained from Cosmo Bio Co., Ltd. Other reagents and solvents were obtained from Wako Pure Chemical Industries Ltd. and Nacalai Tesque Inc. All solvents used were of analytical reagent grade.
Extraction of mucins. Mucin extraction was performed as reported in previous studies $(19,20)$. Briefly, pieces of MEC and NSG tissue were homogenized in cold acetone. The homogenized mixtures were centrifuged at $16,000 \mathrm{x} \mathrm{g}$ at $4^{\circ} \mathrm{C}$ for $10 \mathrm{~min}$. After discarding the supernatants, the resulting powders were homogenized in PBS ( $\mathrm{pH} 7.4,805 \mu \mathrm{l})$ containing $5 \mu \mathrm{l}$ of protease inhibitor mix (GE Healthcare Bio-Sciences). A saturated calcium acetate solution was added to the supernatants at a ratio of 1:4, followed by the addition of three volumes of ethanol. The mixtures were cooled at $-80^{\circ} \mathrm{C}$, left to stand for $1 \mathrm{~h}$, and centrifuged. The precipitates were dissolved in $2 \mathrm{M}$ urea in PBS (pH 7.4, $100 \mu \mathrm{l})$ and centrifuged at $16,000 \mathrm{x} \mathrm{g}$ at $4^{\circ} \mathrm{C}$ for $10 \mathrm{~min}$. The supernatants were transferred into new tubes and precipitated with ethanol, as described above. After centrifugation at $16,000 \times \mathrm{g}$ at $4^{\circ} \mathrm{C}$ for $10 \mathrm{~min}$, the resulting precipitates were dissolved in $8 \mathrm{M}$ urea

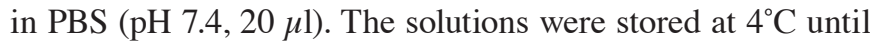
further use.

SMME. SMME membranes were prepared by immersion in a hydrophilic polymer mixture of $\mathrm{PVA}: \mathrm{PVP}=1: 3$ as previously described (24). The SMME membranes (separation length, $6 \mathrm{~cm}$ ) were wetted in methanol and then transferred into a running buffer (0.1 M pyridine-formic acid buffer, $\mathrm{pH}$ 4.0). After equilibration for $30 \mathrm{~min}$ with gentle shaking, the membranes were subjected to electrophoresis. The solutions containing mucins extracted from clinical samples were spotted at $1.5 \mathrm{~cm}$ from the edge of the membrane at the negative node. Electrophoresis was performed using a membrane electrophoresis chamber (EPC105AA; Advantec) in constant-current mode at $1.0 \mathrm{~mA} / \mathrm{cm}$ for $30 \mathrm{~min}$. The membranes were then stained with Alcian blue as previously described $(19,20)$.

Immunostaining. Mucin immunostaining on the SMME membrane was performed as previously reported $(24,25)$. Briefly, the electrophoresed membranes were immersed in acetone for $30 \mathrm{~min}$, followed by heating at $150^{\circ} \mathrm{C}$ for $5 \mathrm{~min}(25,26)$. The membranes were then rewetted by immersing in 5\% BSA in PBS containing 0.05\% Tween-20 (PBS-T) for $1 \mathrm{~h}$. Following washing with PBS-T (5 min, 3 times), the membranes were incubated with PBS-T containing a primary antibody (dilution of $1 / 1,000$ ) at $4^{\circ} \mathrm{C}$ overnight. After washing with PBS-T (5 min, 3 times), the membranes were incubated with PBS-T containing secondary antibody labeled with HRP (dilution of $1 / 2,000$ ) for $1 \mathrm{~h}$ at room temperature. Binding was visualized with ECL reagents (Western Lightning Plus-ECL; PerkinElmer). Chemiluminescence images were obtained using ChemiDoc XRS (Bio-Rad Laboratories, Inc.).

Release and permethylation of $O$-glycans. $O$-glycans were released from mucins on the SMME membranes by reductive $\beta$-elimination, followed by analysis using mass spectrometry, as per previous studies $(19,20)$. Briefly, the stained mucin spots were excised from the SMME membrane, transferred to a $500 \mu \mathrm{l}$ microcentrifuge tube, and incubated with $40 \mu \mathrm{l}$ of $500 \mathrm{mM} \mathrm{NaBH}_{4}$ in $50 \mathrm{mM} \mathrm{NaOH}$ at $45^{\circ} \mathrm{C}$ for $16 \mathrm{~h}$. The reaction mixtures were quenched by adding $4 \mu \mathrm{l}$ of glacial acetic acid until the hydrogen gas ceased. The mixtures were desalted using a cation-exchange-solid-phase extraction cartridge $(3 \mathrm{ml})$ 
Table I. Summary of salivary glands used in the present study.

\begin{tabular}{cccccc}
\hline Sample number & Age, years & Sex & Location & Tissue type & $\begin{array}{c}\text { Histological grade } \\
\text { (TNM classification) }\end{array}$ \\
\hline 1 & 38 & F & Minor salivary gland & Mucoepidermoid carcinoma & Low grade (T1N0M0) \\
2 & 39 & F & Minor salivary gland & Mucoepidermoid carcinoma & Low grade (T1N0M0) \\
3 & 52 & M & Minor salivary gland & Mucoepidermoid carcinoma & Low grade (T2N0M0) \\
4 & 90 & F & Submandibular gland & Normal & Not applicable $^{\text {a }}$ \\
5 & 68 & F & Submandibular gland & Normal & Not applicable $^{\text {a }}$ \\
6 & 57 & F & Submandibular gland & Normal & Not applicable $^{\text {a }}$ \\
7 & 41 & M & Submandibular gland & Normal & Not applicable $^{\text {a }}$ \\
8 & 55 & M & Submandibular gland & Normal & Not applicable $^{\mathrm{a}}$ \\
9 & 51 & M & Sublingual gland & Normal & Not applicable $^{\mathrm{a}}$ \\
10 & 87 & M & Minor salivary gland & Normal & Not applicable $^{\mathrm{a}}$
\end{tabular}

${ }^{a}$ TNM classification is not applicable to normal tissues; F, female; M, male.

(Oasis MCX; Waters Corp.) and concentrated. The obtained residues were dissolved in $100 \mu \mathrm{l}$ of $1 \%$ (v/v) acetic acid in methanol and dried again using a centrifugal evaporator. The dissolving and drying procedures were repeated.

A slurry of $50 \mu 1(80 \mathrm{mg} / \mathrm{ml})$ of $\mathrm{NaOH}$ in dimethyl sulfoxide (DMSO) containing 1\% (v/v) distilled water was added to the dried samples, followed by $12.5 \mu \mathrm{l}$ of methyl iodide. The mixtures were then vigorously shaken for 30 min until the sodium iodide precipitated. After adding $50 \mu \mathrm{l}$ of $10 \%$ acetic acid, the mixtures were diluted to $1 \mathrm{ml}$ with distilled water. The diluted solutions were subjected to a solid-phase extraction cartridge (50 mg) (Sep-Pak C18; Waters Corp.), washed with $1 \mathrm{ml}$ of water three times, and then dried. Finally, permethylated glycans were eluted with $1 \mathrm{ml}$ of $50 \%$ acetonitrile and concentrated using a centrifugal evaporator.

$M S$. The MS spectra of the permethylated glycans were acquired in reflectron positive ion mode using a matrix-assisted laser desorption ionization (MALDI)-time-of-flight (TOF) mass spectrometer (UltraFlex; Bruker-Daltonics) equipped with a $337 \mathrm{~nm}$ pulsed nitrogen gas laser. 2,5-Dihydroxybenzoic acid (2,5-DHB) was used as the matrix. For sample preparation, $0.5 \mu \mathrm{l}$ of 2,5 -DHB solution $(10 \mathrm{mg} / \mathrm{ml}$ in $30 \%$ ethanol) was deposited onto a MALDI target plate and dried. Then $0.5 \mu \mathrm{l}$ of the sample solution was deposited over the dried spot of 2,5-DHB and dried. Tandem mass spectrometry was performed using a MALDI-quadrupole ion trap (QIT)-TOF mass spectrometer (AXIMA-QIT; Shimadzu Corp.) in a positive ion mode. Argon gas was used as the collision gas for collision-induced dissociation.

Statistical analysis. The relative intensities of the glycan signals in the MS spectra were calculated as a percentage of the intensity in the sum of the intensities of all observed 50 glycans. Unpaired Student's t-tests for each glycan between MEC and NSGs were performed using GraphPad Prism 8.4.2 (GraphPad Software). The MS/MS spectra of the permethylated glycans were assigned using GlycoWorkBench 2.1 (http://www.eurocarbdb.org/).
Glycan cartoon. The glycan structures were depicted using CFG graphical notation for glycans (http://www. functionalglycomics.org/static/consortium/CFGnomenclature. pdf).

\section{Results}

SMME analyses of MEC and NSGs. The clinical information of the salivary glands of MEC and NSGs used in this study are summarized in Table I. The mucins extracted from the salivary glands were separated by SMME and stained with Alcian blue (Fig. 1A). A commercially obtained PGM containing chondroitin sulfate, hyaluronic acid, acidic mucin, and neutral mucin was used as the reference material in SMME. We estimated the stained bands by comparing the migrating positions with those of the corresponding constituents in the reference PGM. Additionally, the mucin-enrichment fraction of cultured cells (HPAF-II) was also used as a reference material containing MUC1 (25). All MEC samples 1-3 and NSGs of the minor salivary gland 10 clearly showed bands at the migrating position of the acidic mucin in the reference PGM. Another dark band was observed at the position of neutral mucin only from the NSG sample 7. Other samples showed a pale band at a lower position of the neutral mucin and/or the same position of hyaluronic acid in the reference PGM.

We also stained the SMME membranes with specific probes, such as a monoclonal antibody. Anti-MUC1 antibody (MY.1E12) revealed that all three MEC samples contained MUC1 but not NSGs, and the migrating positions of these MUC1 bands were just below that of MUC1 in HPAF-II (Fig. 1B). On the other hand, the mucins of the minor salivary gland 10 were not stained even by increasing the exposure time of chemiluminescence reaction (Fig. S1A). MUC1 and hyaluronic acid appeared close in the SMME. To confirm hyaluronic acid, we also stained the SMME membrane with HABP (Fig. 1C). Hyaluronic acid was detected in all samples at the same migration position as the reference hyaluronic acid in PGM. 
A

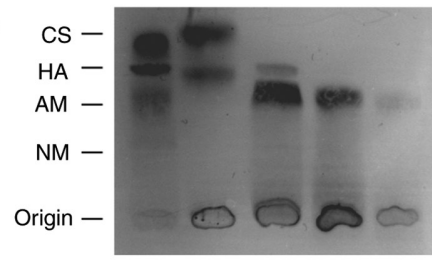

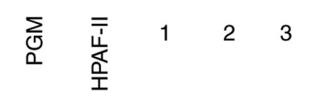

B

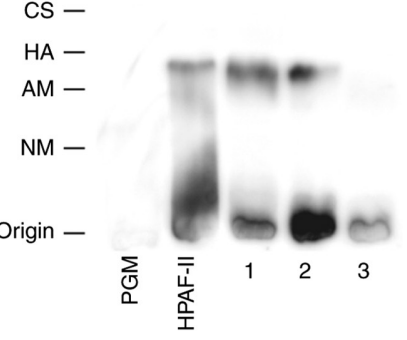

C

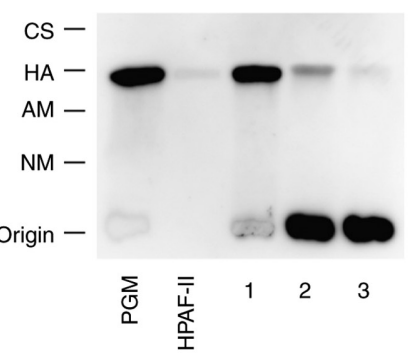

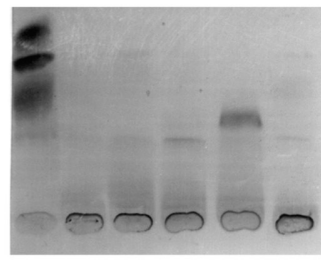
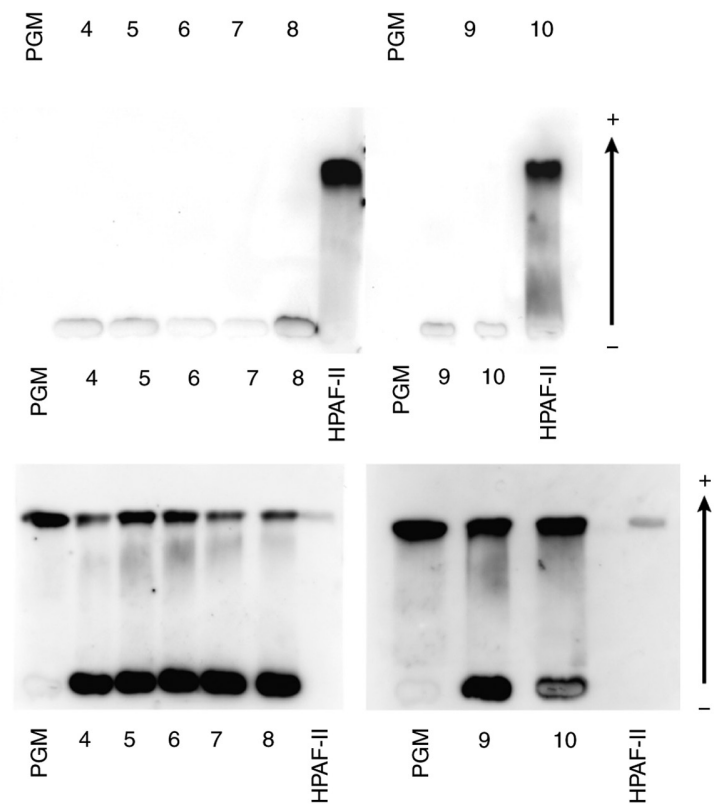

Figure 1. Mucins of mucoepidermoid carcinoma and normal salivary glands were separated by SMME. Arabic numerals indicate the sample numbers shown in Table I. PGM was used as a reference mixture of CS, HA, AM and NM. The migrating position of the neutral mucin of PGM was estimated from our previous study (18). HPAF-II lysate was used as a mixture containing MUC1. (A) Alcian blue staining of the SMME membranes. (B) Staining with anti-MUC1 antibody (MY.1E12). (C) Staining with hyaluronan binding protein (BC-40). AM, acidic mucin; CS, chondroitin sulfate; HA, hyaluronic acid; MUC1, mucin 1; NM, neutral mucin; PGM, porcine gastric mucin; SMME, supported molecular matrix electrophoresis.
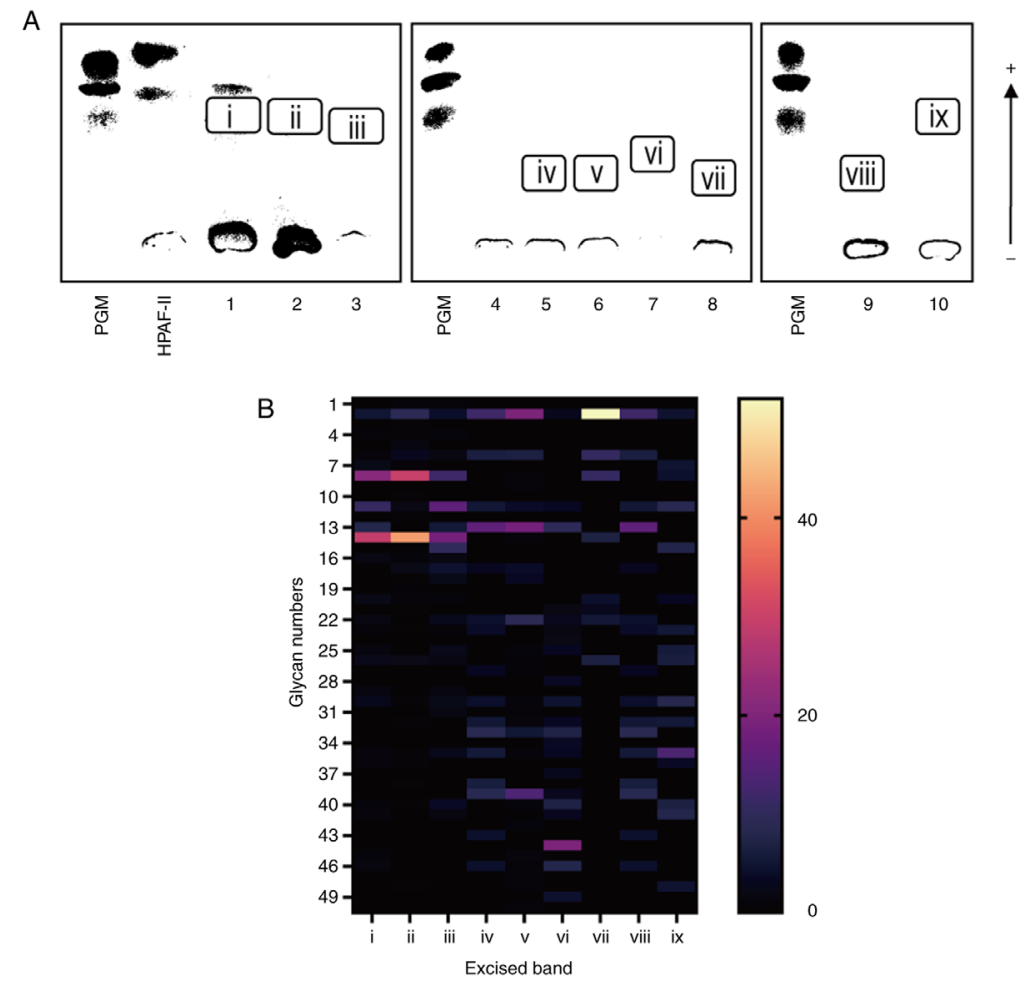

Figure 2. $O$-glycan profiles of mucins separated by SMME. (A) Position of the excised bands in the illustration derived from the SMME membranes stained with Alcian blue (Fig. 1A). Roman numerals indicate the excised band numbers. No bands appeared from sample 4. (B) Heatmap of $O$-glycan profiles of the excised bands. The color scale indicates the relative intensity (\%) of each glycan to the sum of intensities of all 50 glycans (Table II). PGM, porcine gastric mucin; SMME, supported molecular matrix electrophoresis. 
Table II. Summary of MS signals of $O$-glycans detected from the excised band (Fig. 2A).

A, Acidic glycans

\begin{tabular}{|c|c|c|c|}
\hline Glycan no. & Composition & Calcd, $m / z^{\mathrm{a}}$ & Obsd, $m / z^{\mathrm{b}}$ \\
\hline 1 & $(\mathrm{HexNAc})_{1}(\mathrm{NeuAc})_{1}$ & 691.36 & 691.37 \\
\hline 2 & $(\mathrm{Hex})_{1}(\mathrm{HexNAc})_{1}(\mathrm{NeuAc})_{1}$ & 895.46 & 895.49 \\
\hline 3 & $(\mathrm{HexNAc})_{2}(\mathrm{NeuAc})_{1}$ & 936.49 & 936.54 \\
\hline 4 & $(\mathrm{Hex})_{1}(\mathrm{HexNAc})_{1}(\text { Deoxyhexose })_{1}(\mathrm{NeuAc})_{1}$ & $1,069.55$ & $1,069.58$ \\
\hline 5 & $(\mathrm{Hex})_{1}(\mathrm{HexNAc})_{2}(\mathrm{NeuAc})_{1}$ & $1,140.59$ & $1,140.64$ \\
\hline 6 & $(\mathrm{Hex})_{1}(\mathrm{HexNAc})_{1}(\mathrm{NeuAc})_{2}$ & $1,256.64$ & $1,256.67$ \\
\hline 7 & $(\text { Hex })_{1}(\text { HexNAc })_{2}(\text { Deoxyhexose })_{1}(\text { NeuAc })_{1}$ & $1,314.68$ & $1,314.71$ \\
\hline 8 & $(\mathrm{Hex})_{2}(\mathrm{HexNAc})_{2}(\mathrm{NeuAc})_{1}$ & $1,344.69$ & $1,344.74$ \\
\hline 9 & $(\text { Hex })_{2}(\text { HexNAc })_{1}(\text { Deoxyhexose })_{2}(\text { NeuAc })_{1}$ & $1,447.74$ & $1,447.79$ \\
\hline 10 & $(\mathrm{Hex})_{1}(\mathrm{HexNAc})_{2}(\mathrm{NeuAc})_{2}$ & $1,501.76$ & $1,501.81$ \\
\hline 11 & $(\mathrm{Hex})_{2}(\mathrm{HexNAc})_{2}(\text { Deoxyhexose })_{1}(\mathrm{NeuAc})_{1}$ & $1,518.78$ & $1,518.82$ \\
\hline 12 & $(\mathrm{Hex})_{2}(\mathrm{HexNAc})_{3}(\mathrm{NeuAc})_{1}$ & $1,589.82$ & $1,589.86$ \\
\hline 13 & $(\mathrm{Hex})_{2}(\mathrm{HexNAc})_{2}(\text { Deoxyhexose })_{2}(\mathrm{NeuAc})_{1}$ & $1,692.87$ & $1,692.89$ \\
\hline 14 & $(\mathrm{Hex})_{2}(\mathrm{HexNAc})_{2}(\mathrm{NeuAc})_{2}$ & $1,705.86$ & $1,705.88$ \\
\hline 15 & $(\mathrm{Hex})_{2}(\mathrm{HexNAc})_{3}(\text { Deoxyhexose })_{1}(\mathrm{NeuAc})_{1}$ & $1,763.90$ & $1,763.94$ \\
\hline 16 & $(\mathrm{Hex})_{3}(\mathrm{HexNAc})_{3}(\mathrm{NeuAc})_{1}$ & $1,793.92$ & $1,793.90$ \\
\hline 17 & $(\mathrm{Hex})_{2}(\mathrm{HexNAc})_{2}(\text { Deoxyhexose })_{1}(\mathrm{NeuAc})_{2}$ & $1,879.95$ & $1,880.01$ \\
\hline 18 & $(\mathrm{Hex})_{2}(\mathrm{HexNAc})_{3}(\text { Deoxyhexose })_{2}(\mathrm{NeuAc})_{1}$ & $1,937.99$ & $1,938.03$ \\
\hline 19 & $(\mathrm{Hex})_{2}(\mathrm{HexNAc})_{3}(\mathrm{NeuAc})_{2}$ & $1,950.99$ & $1,951.06$ \\
\hline
\end{tabular}

B, Neutral glycans

\begin{tabular}{|c|c|c|c|}
\hline Glycan no. & Composition & Calcd, $m / z^{\mathrm{a}}$ & Obsd, $m / z^{\mathrm{b}}$ \\
\hline 20 & $(\mathrm{Hex})_{1}(\mathrm{HexNAc})_{1}$ & 534.29 & 534.28 \\
\hline 21 & $(\mathrm{HexNAc})_{2}$ & 575.32 & 575.18 \\
\hline 22 & $(\text { Hex })_{1}(\text { HexNAc })_{1}(\text { Deoxyhexose })_{1}$ & 708.38 & 708.40 \\
\hline 23 & $(\mathrm{Hex})_{1}(\mathrm{HexNAc})_{2}$ & 779.41 & 779.44 \\
\hline 24 & $(\mathrm{Hex})_{2}(\mathrm{HexNAc})_{1}(\text { Deoxyhexose })_{1}$ & 912.48 & 912.46 \\
\hline 25 & $(\mathrm{Hex})_{1}(\mathrm{HexNAc})_{2}(\text { Deoxyhexose })_{1}$ & 953.50 & 953.54 \\
\hline 26 & $(\mathrm{Hex})_{2}(\mathrm{HexNAc})_{2}$ & 983.52 & 983.57 \\
\hline 27 & $(\mathrm{Hex})_{1}(\mathrm{HexNAc})_{3}$ & $1,024.54$ & $1,024.59$ \\
\hline 28 & $(\operatorname{Hex})_{2}(\text { HexNAc })_{1}(\text { Deoxyhexose })_{2}$ & $1,086.57$ & $1,086.53$ \\
\hline 29 & $(\mathrm{Hex})_{1}(\mathrm{HexNAc})_{2}(\text { Deoxyhexose })_{2}$ & $1,127.59$ & $1,127.63$ \\
\hline 30 & $(\mathrm{Hex})_{2}(\mathrm{HexNAc})_{2}(\text { Deoxyhexose })_{1}$ & $1,157.60$ & $1,157.64$ \\
\hline 31 & $(\mathrm{Hex})_{1}(\mathrm{HexNAc})_{3}(\text { Deoxyhexose })_{1}$ & $1,198.63$ & $1,198.69$ \\
\hline 32 & $(\mathrm{Hex})_{2}(\mathrm{HexNAc})_{3}$ & $1,228.64$ & $1,228.68$ \\
\hline 33 & $(\mathrm{Hex})_{2}(\mathrm{HexNAc})_{2}(\text { Deoxyhexose })_{2}$ & $1,331.69$ & $1,331.75$ \\
\hline 34 & $(\mathrm{Hex})_{3}(\mathrm{HexNAc})_{2}(\text { Deoxyhexose })_{1}$ & $1,361.70$ & $1,361.66$ \\
\hline 35 & $(\text { Hex })_{2}(\text { HexNAc })_{3}(\text { Deoxyhexose })_{1}$ & $1,402.73$ & $1,402.78$ \\
\hline 36 & $(\mathrm{Hex})_{3}(\mathrm{HexNAc})_{3}$ & $1,432.74$ & $1,432.75$ \\
\hline 37 & $(\text { Hex })_{3}(\text { HexNAc })_{1}(\text { Deoxyhexose })_{3}$ & $1,464.76$ & $1,464.69$ \\
\hline 38 & $(\mathrm{Hex})_{2}(\mathrm{HexNAc})_{4}$ & $1,473.77$ & $1,473.83$ \\
\hline 39 & $(\mathrm{Hex})_{2}(\mathrm{HexNAc})_{2}(\text { Deoxyhexose })_{3}$ & $1,505.78$ & $1,505.81$ \\
\hline 40 & $(\mathrm{Hex})_{2}(\mathrm{HexNAc})_{3}(\text { Deoxyhexose })_{2}$ & $1,576.82$ & $1,576.85$ \\
\hline 41 & $(\mathrm{Hex})_{3}(\mathrm{HexNAc})_{3}(\text { Deoxyhexose })_{1}$ & $1,606.83$ & $1,606.82$ \\
\hline 42 & $(\mathrm{Hex})_{4}(\mathrm{HexNAc})_{3}$ & $1,636.84$ & $1,636.94$ \\
\hline 43 & $(\mathrm{Hex})_{2}(\mathrm{HexNAc})_{4}(\text { Deoxyhexose })_{1}$ & $1,647.86$ & $1,647.88$ \\
\hline 44 & $(\mathrm{Hex})_{3}(\mathrm{HexNAc})_{2}(\text { Deoxyhexose })_{3}$ & $1,709.88$ & $1,709.81$ \\
\hline 45 & $(\mathrm{Hex})_{2}(\mathrm{HexNAc})_{3}(\text { Deoxyhexose })_{3}$ & $1,750.91$ & $1,750.96$ \\
\hline
\end{tabular}


Table II. Continued.

B, Neutral glycans

\begin{tabular}{llll}
\hline Glycan no. & \multicolumn{1}{c}{ Composition } & Calcd, $m / z^{\mathrm{a}}$ & Obsd, $m / z^{\mathrm{b}}$ \\
\hline 46 & $(\mathrm{Hex})_{3}(\text { HexNAc })_{3}(\text { Deoxyhexose })_{2}$ & $1,780.92$ & $1,780.95$ \\
47 & $(\mathrm{Hex})_{2}(\text { HexNAc })_{4}(\text { Deoxyhexose })_{2}$ & $1,821.95$ & $1,822.05$ \\
48 & $(\mathrm{Hex})_{3}(\text { HexNAc })_{4}(\text { Deoxyhexose })_{1}$ & $1,851.96$ & $1,852.00$ \\
49 & $(\mathrm{Hex})_{3}(\text { HexNAc })_{3}(\text { Deoxyhexose })_{3}$ & $1,955.01$ & $1,954.90$ \\
50 & $(\text { Hex })_{2}(\text { HexNAc })_{4}(\text { Deoxyhexose })_{3}$ & $1,996.04$ & $1,996.10$ \\
\hline
\end{tabular}

${ }^{\mathrm{a}}$ All signals were calculated as $[\mathrm{M}+\mathrm{Na}]^{+}$ions. ${ }^{\mathrm{b}}$ The observed $\mathrm{m} / \mathrm{z}$ values are the averages of the corresponding signals detected in all spectra. All glycans were permethylated before MS acquisition. The $\mathrm{m} / \mathrm{z}$ values are monoisotopic. Calcd, calculated; MS, mass spectrometry; Obsd, observed.
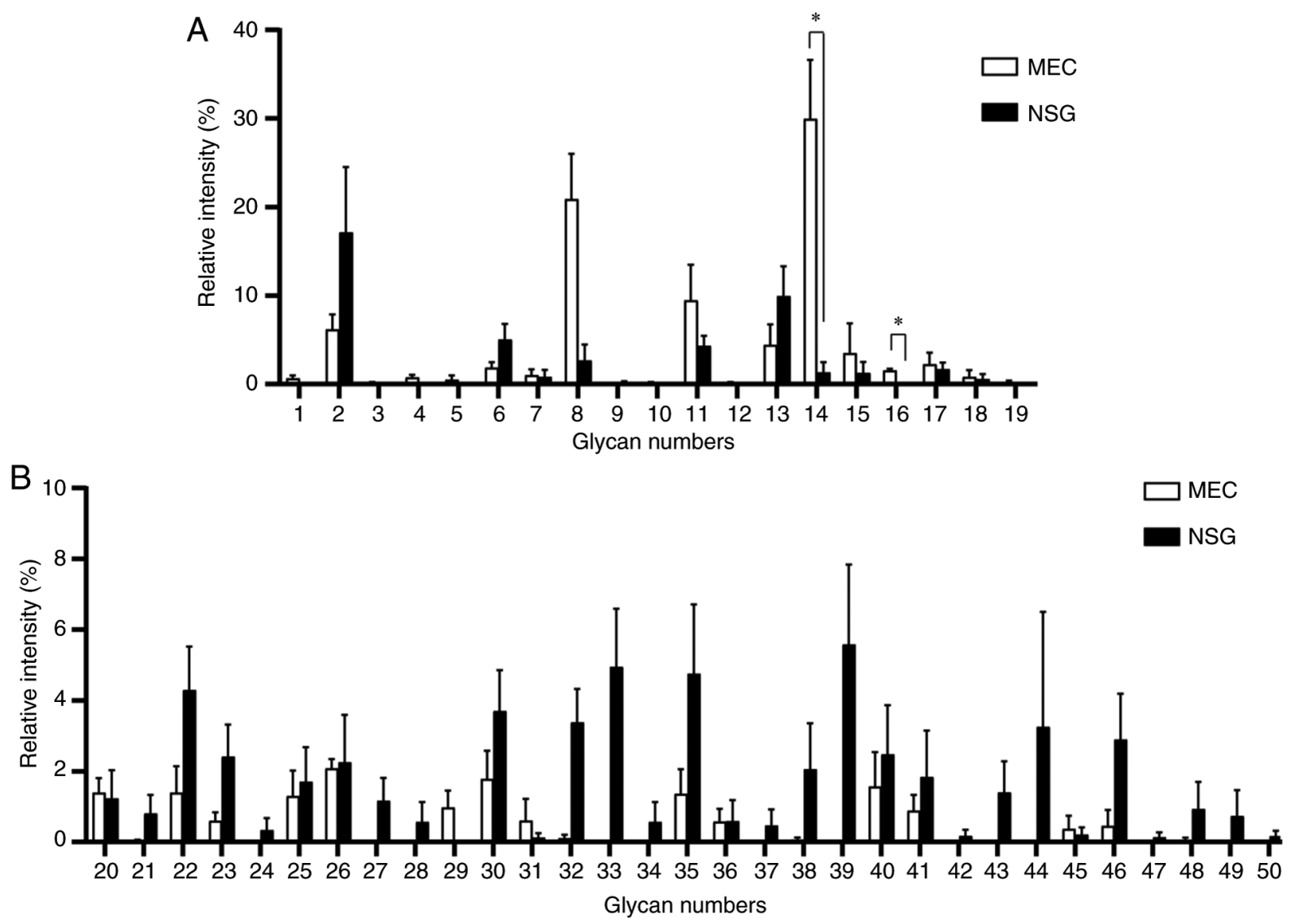

Figure 3. Two-group comparisons of all glycan signals between MEC and NSGs. Bar height represents the mean of the relative intensity of the three bands (i, ii and iii) for MEC (white) and six bands (iv-ix) for NSGs (black). Error bars indicate the SEM. "P<0.001. (A) Sialoglycans and (B) neutral glycans. MEC, mucoepidermoid carcinoma; NSG, normal salivary gland.

Comparison of O-glycans on mucins between MEC and NSGs. Each band of mucin stained with Alcian blue was excised and subjected to reductive $\beta$-elimination, in which the $O$-glycans attached to mucins were released and reduced to the corresponding alditols (Fig. 2A). The obtained glycan alditols were permethylated and analyzed using MALDI-TOF MS. All of the observed glycan signals were categorized into two groups: Sialoglycans and neutral glycans, as summarized in Table II. The relative intensities of the glycan signals observed from each band are depicted in heatmap (Fig. 2B). The
$O$-glycans from MEC (i-iii) mostly consisted of sialoglycans 8 and 14 (orange cells), while the $O$-glycans from NSGs (iv-ix) contained substantial neutral glycans (navy blue cells). This is a distinctive difference in the glycan profiles of MEC and NSGs. In all of the observed glycan signals, the mean relative intensities in the two groups MEC (i-iii) and NSG (iv-ix) were compared (Fig. 3). Notably, glycan 8 and 14 showed high intensities in MEC compared with NSGs. These glycans were mono-sialylated and di-sialylated of a common core structure $(\mathrm{Hex})_{2}(\mathrm{HexNAc})_{2}$, respectively. Glycan 1 is 
A

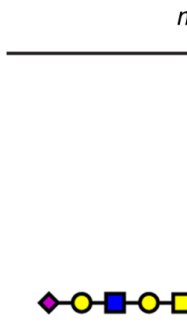

Core 1 type

B $(0-a)\left(\begin{array}{c}\hat{\circ} \\ 10-0)\end{array}\right)$
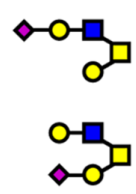

Core 2 type $m / z 1793$

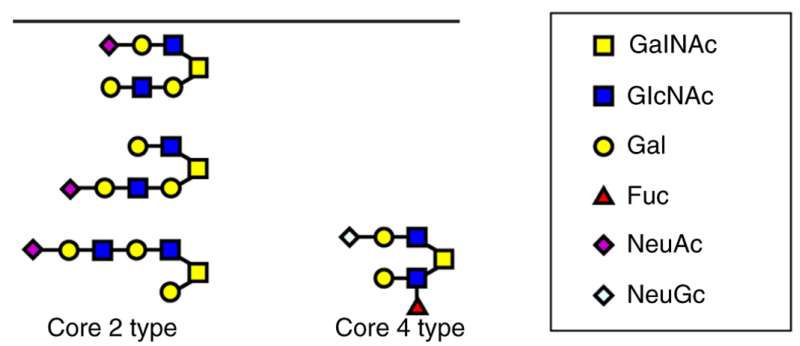

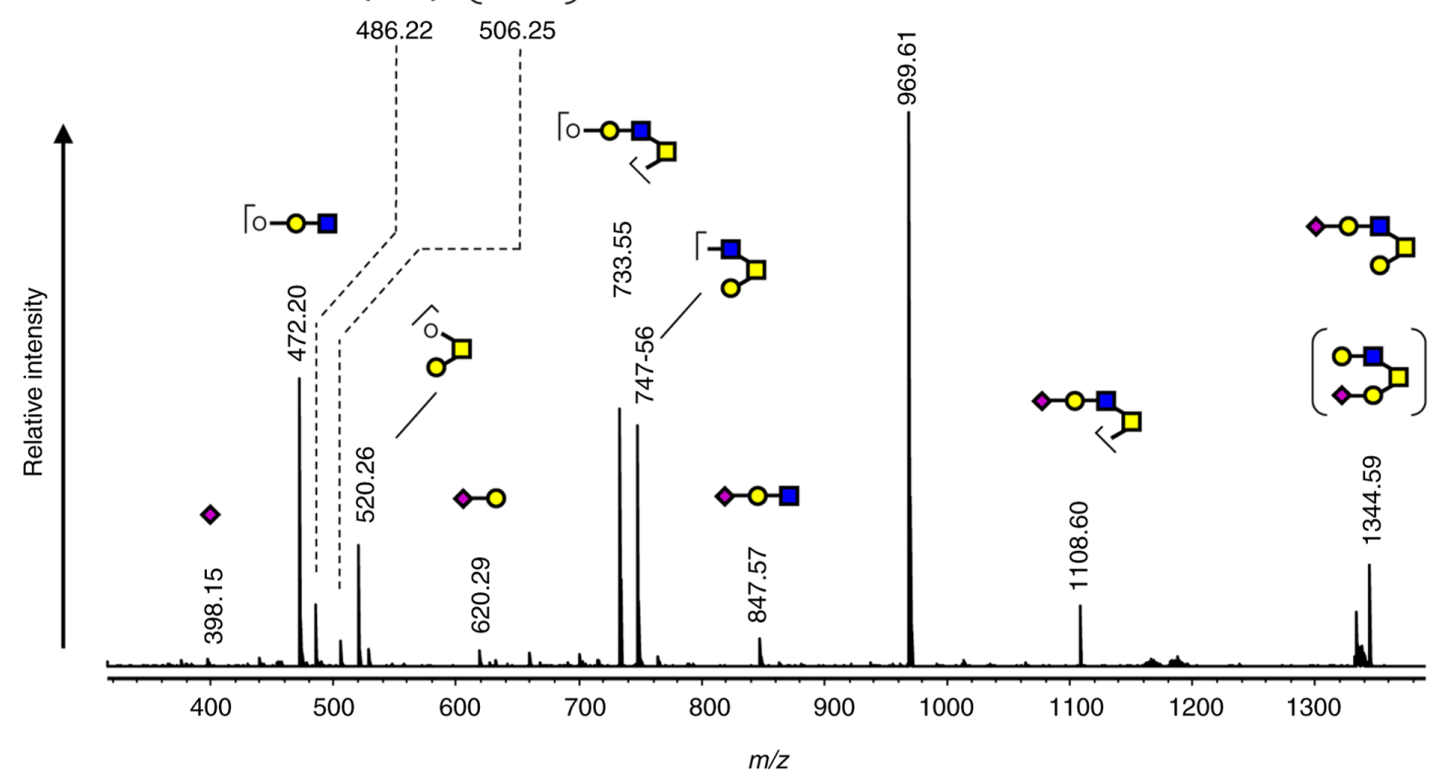

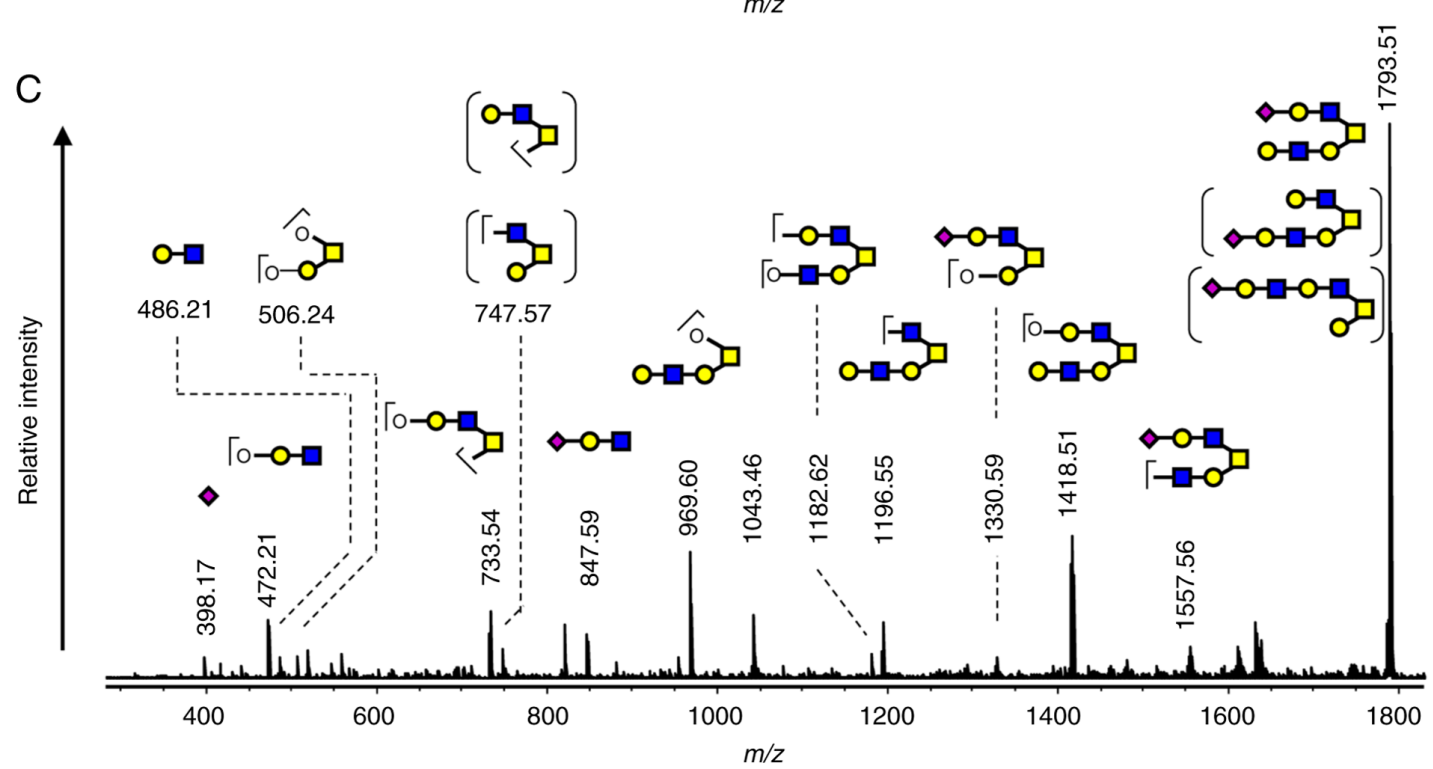

Figure 4. Proposed structures for the two significant glycans, glycan $8(\mathrm{~m} / \mathrm{z}, 1,344)$ and $16(\mathrm{~m} / \mathrm{z}, 1,793)$. (A) Possible structures for glycans 8 ( $m / z, 1,344)$ and 16 ( $m / z, 1,793)$ based on the biosynthetic pathway. (B) MS/MS spectrum of glycan $8(\mathrm{~m} / z, 1,344)$. (C) MS/MS spectrum of glycan 16 ( $m / z, 1,793)$. The proposed structure and assignment of the fragment ions are indicated in the spectra. The structures in parentheses are considered to be minor components. MS/MS, tandem mass spectrometry.

sialyl Tn antigen, a well-known glycan biomarker for various malignant tumors $(27,28)$, and was detected in two out of three MEC samples, but not in the NSG samples. On the other hand, many highly fucosylated neutral glycans (glycan 33, 35, 39, and 44) were abundantly observed in NSGs.
Structural analysis of the glycans from MEC. The significant glycan 8 and 14 were mono- and di-sialylated structures of the same core structure $(\mathrm{Hex})_{2}(\mathrm{HexNAc})_{2}$, respectively. Another significant glycan, glycan 16, is the mono-sialylated structure of $(\mathrm{Hex})_{3}(\mathrm{HexNAc})_{3}$. To elucidate the core structures of the 
significant glycans in MEC, we acquired the MS/MS spectra of glycan 8 and 16. Based on the biosynthetic pathway of the $O$-glycans, we proposed potential structures for glycans $8(\mathrm{~m} / \mathrm{z}, 1,344)$ and $16(\mathrm{~m} / \mathrm{z}, 793)$, respectively (Fig. 4A). The MS/MS spectrum of glycan $8(\mathrm{~m} / \mathrm{z}, 1,344)$ revealed that glycan 8 was a mixture of the positional isomers of sialylation of the same structure that was galactosylated at the GlcNAc of core 2 (Fig. 4B). The MS/MS spectrum of glycan $16(\mathrm{~m} / \mathrm{z}, 1,973)$ was in agreement with the calculated fragments of the $\mathrm{N}$-acetyl lactosamine (LacNAc) elongated core 2 (Fig. 4C).

\section{Discussion}

In this study, MEC was found to abundantly produce MUC1, which was characteristically modified with core 2 type sialoglycans. The secretion of mucins in the oral cavity and the number of sialic acids on the mucins have been reported to decrease with aging (29). MEC samples 1 and 2 and NSG sample 7 were obtained from middle-aged patients (38-41 years old) and showed dark bands in Alcian blue staining during SMME analysis, while other samples from patients over 50 years of age showed pale bands. This is consistent with the previous report described above. MUC1 is involved in cell proliferation and signal transduction $(11,30)$ and has been known to be overexpressed in malignant tumors (31). Immunohistochemistry using the MUC1 antibody showed that higher levels of MUC1 expression were positively correlated with the malignancy and prognosis of MEC $(17,18)$. In our experiments, MUC1 was only detected in MEC. Although MEC sample 3 appeared to be MUC1-negative, all three MEC samples became MUC1-positive by increasing the exposure time of chemiluminescence imaging (Fig. S1A). On the other hand, all NSGs in our experiment were found to be MUC1-negative. The incidence of MEC is high in relatively young patients (average age: 48.8 years old) (32). Notably, MUC1 was not detected even in the NSGs of relatively young patients $(6,7,8,9: 41-57$ years old). MUC1 is expressed as a membrane-bound mucin in the ducts of all normal salivary gland tissues $(33,34)$.In the present study, only the water-soluble fraction was analyzed, suggesting that the expression of water-soluble MUC1 was closely related to the development of MEC. The MUC1 antibody, MY.1E12, recognizes MUC1 with a sialyl T (Neu5Aca2-3Gal/1-3GalNAc) structure (23). We could not deny that NSGs produce MUC1 without this sialyl $\mathrm{T}$ structure. To clarify this point, the SMME membranes were stained using another anti-MUC1 antibody, VU4H5 which recognizes a tandem repeat domain of MUC1. The results supported the finding that MEC but not the NSGs expressed MUC1 (Fig. S1B). The origin spots of the MEC samples were strongly stained, which suggested that MUC1 exists in its insoluble form in the sample solution (Fig. S1 A and B). MUC1, one of the membrane-bound mucins, has a cleavage site in the extracellular domain $(35,36)$. The cleaved MUC1 is able to migrate to the upper part during SMME, while the membrane-bound form remains in the origin. On the Alcian blue stained membrane, NSG sample 10 showed a mucin band at almost the same position as MUC1 from the MEC samples. However, the band could not be stained with either of the MUC1 antibodies, MY.1E12 and VU4H5 (Fig. S1).
All of the MEC samples in this study were obtained from minor salivary glands. For NSG, samples 4-8 were obtained from submandibular glands, while samples 9 and 10 were obtained from the sublingual gland and the minor salivary gland, respectively. The difference in the types of salivary glands may affect mucin expression. The staining of the SMME membranes with Alcian blue showed clear differences between the minor salivary glands (1-3, and 10) and submandibular glands (4-8). Moreover, the sublingual gland (9) was different from the other two types. Although the number of cases will need to be increased to confirm differences depending on the type of salivary gland, the fact that MUC1 was only detected in MEC (1-3), and not NSGs (10), obtained from minor salivary glands is a key result. In the present study, only three MEC samples were compared with the NSGs. It would have been better if we could have compared MEC lesions and normal areas in the same patients, but all of the MEC in this study were minor salivary glands, and we could not clearly distinguish between normal areas and lesions. Therefore, we cannot deny that individual differences may have affected the present results. In the future, we plan to conduct similar experiments involving the analyses of MECs in the major salivary glands and other mucus-producing salivary gland tumors, such as acinic cell carcinoma, low-grade salivary duct carcinoma, mammary analog secretory carcinoma, and mucinous variant of myoepithelioma, all of which are MUC1 positive (37-40). We thereby aim to clarify whether the origin and types of salivary gland tumors affect the glycan structure of tumor-associated MUC1.

The glycan profiles of mucin were also clearly different between MEC (i-iii) and NSG (iv-ix) The glycans from the MEC mucins largely consisted of sialoglycans, while those from NSG mucins contained many neutral glycans. Although sialic acids have been reported to decrease with aging (29), NSG mucin (vi) from the submandibular gland of a 41-year-old patient had fewer sialoglycans and NSG mucin (vii) compared to the submandibular gland of a 55-year-old patient, whose glycan profile showed a high ratio of sialoglycans. It was also unclear whether the types of salivary glands had an effect on the glycan profiles of the mucins in our experiment. In the two group comparisons between MEC and NSG, the intensities of glycan 8 and 14 were found to be significantly high in MEC. The two glycans were sialylated core 2 glycans. The mRNA expression of core $2-\beta-1,6-N$-acetylglucosaminyltransferase-1 (GCNT1), one of the key enzymes responsible for the core 2 branched structure, is associated with the progression of several cancers, including colorectal cancer, pulmonary adenocarcinoma, and prostate cancer (41-43). It has also been suggested that MUC1 carrying core 2 glycans contribute to the ability of cancer cells to evade attack by natural killer cells (44). Thus, MUC 1 carrying core 2 glycans expressed in MEC may play an important role in malignant cellular behavior. The sialyl Tn (STn) antigen has been widely reported as a tumor-associated glycan antigen. In the present study, STn (glycan 1) was only detected in MEC samples, but with a very small intensity. The STn antigen in MUC1 has potential as a specific biomarker for MEC, however, the sialylated core 2 glycans described above are more 
likely to be used as biomarkers because of their prominent intensities. It has also been reported that the sialic acid levels are increased in malignant tumors (45), which is in good agreement with our results. The abnormal sialylation of cancer cells is a characteristic alteration associated with malignant properties, including invasiveness and metastatic potential (46). Although it has been reported that high MUC1 expression is positively correlated with malignancy, it is still unclear whether the glycan structures of the tumor-associated MUC1 are correlated to the MEC grade because our experiments used only low-grade MEC samples. Using immunohistochemistry, a previous study revealed that the positivity rate of Tn and Lewis a is decreased in high-grade MEC (28). We intend to obtain experimental data on the correlation between the grades and glycan structures of tumor-associated MUC1 in the water-soluble fractions of MEC samples in the future.

In this study, we analyzed the soluble fractions obtained from the homogenates of salivary glands and identified a characteristic mucin, namely MUC1 with sialylated core 2 glycans. Unlike MUC7, which is secreted by goblet cells via exocytosis from the salivary glands into the saliva, MUC1 is usually not secreted, even in the case of soluble MUC1, which is cleaved at the extracellular domain. Soluble MUC1 may enter the blood circulation from lesion areas and has potential for use as a serum biomarker for several tumors that produce MUC1 with characteristic glycans, such as STn and sialyl Lewis a (47). A previous study reported that the serum levels of CA153, a MUC1 antigen recognized by the two anti-MUC1 antibodies DF3 and 115D8, are elevated in some diseases, including various cancers, type 2 diabetes, and coronary heart disease (48). The authors proposed that pathological leakage of CA153 from the epithelium, in addition to the decreased CA153 clearance rate may cause the MUC1 antigen to appear in the blood of patients with the aforementioned diseases. When MUC1 with sialylated core 2 glycans can be used as a serum biomarker for MEC, CA153 in the serum of patients with these diseases may be a confounding variable for tumor-associated MUC1 from MEC. To avoid such confusion, it may be important to distinguish the differences in the glycans of MUC1. KL6 for lung disease and WFA-positive MUC1 for intrahepatic cholangiocarcinoma are known examples in which the glycans of MUC1 differ among primary tumor tissues $(49,50)$. Regrettably, there is no information on the glycans of MUC1 in salivary glands. To clarify these issues in the future, it is necessary to analyze the expression of MUC1, including its glycans, in other oral tumors, and investigate its leakage into the bloodstream.

\section{Acknowledgements}

Not applicable.

\section{Funding}

The present study was partially supported by the Japan Society for the Promotion of Science KAKENHI (grant nos. JP17H03808 and JP17K19627) and the Mizutani Foundation for Glycoscience (grant no. 200049).

\section{Availability of data and materials}

The datasets generated and/or analyzed during the current study are available in the MassIVE repository (https://massive. ucsd.edu/ProteoSAFe/dataset.jsp?task=441d55f0338f4e09a75 d00be9f0acbc0; accession no. MSV000087578).

\section{Authors' contributions}

EI, TN, KK, UA and AK designed the study. KH performed pathological evaluation of the salivary glands. EI, TS and AK performed SMME and glycan analysis. EI, TS and AK confirmed the authenticity of all the raw data. EI and AK interpreted the acquired data and prepared the manuscript. TN, KK and UA contributed to critical revision of the manuscript for important intellectual content. All authors read and approved the final manuscript.

\section{Ethics approval and consent to participate}

This research was approved by the Tokyo Dental College Ichikawa General Hospital Ethics Review Committee (approval no. I16-74; Ichikawa, Japan) and the AIST Committee on Bioethics of Experiments Involving Human-derived Materials (approval no. h-213; Tokyo, Japan). Written informed consent was obtained for experimentation with human subjects.

\section{Patient consent for publication}

Not applicable.

\section{Competing interests}

The authors declare that they have no competing interests.

\section{References}

1. EI-Naggar AK, Chan JKC, Grandis JR, Takata T and Slootweg PJ (eds): WHO classification of head and neck tumors. 4th edition. IARC Press, Lyon, 2017.

2. Diwakar JK, Agarwal A, Garg C, Giri KY, Dandriyal R and Kumar G: A rare case of mucoepidermoid carcinoma of parotid with mandibular metastasis. Ann Maxillofac Surg 9: 205-207, 2019.

3. Janet-Ofelia GC, Rafael MV, Guillermo GA, Carlos-Enrique CV, José-Martín RM, Henry GM and Jaime-Enrique MG: Mucoepidermoid carcinoma of the salivary glands: Survival and prognostic factors. J Maxillofac Oral Surg 16: 431-437, 2017.

4. Liu S, Ow A, Ruan M, Yang W, Zhang C, Wang L and Zhang C: Prognostic factors in primary salivary gland mucoepidermoid carcinoma: An analysis of 376 cases in an Eastern Chinese population. Int J Oral Maxillofac Surg 43: 667-673, 2014.

5. Pusztaszeri MP and Faquin WC: Update in salivary gland cytopathology: Recent molecular advances and diagnostic applications. Semin Diagn Pathol 32: 264-274, 2015.

6. Lombardi D, McGurk M, Vander Poorten V, Guzzo M, Accorona R, Rampinelli V and Nicolai P: Surgical treatment of salivary malignant tumors. Oral Oncol 65: 102-113, 2017.

7. Brandwein MS, Ferlito A, Bradley PJ, Hille JJ and Rinaldo A: Diagnosis and classification of salivary neoplasms: Pathologic challenges and relevance to clinical outcomes. Acta Otolaryngol 122: 758-764, 2002.

8. Stowell SR, Ju T and Cummings RD: Protein glycosylation in cancer. Annu Rev Pathol 10: 473-510, 2015.

9. Varki A: Biological roles of oligosaccharides: All of the theories are correct. Glycobiology 3: 97-130, 1993. 
10. Adamczyk B, Tharmalingam T and Rudd PM: Glycans as cancer biomarkers. Biochim Biophys Acta 1820: 1347-1353, 2012.

11. Gendler SJ: MUC1, the renaissance molecule. J Mammary Gland Biol Neoplasia 6: 339-353, 2001.

12. Pinto R, Carvalho AS, Conze T, Magalhães A, Picco G, Burchell JM, Taylor-Papadimitriou J, Reis CA, Almeida R, Mandel U, et al: Identification of new cancer biomarkers based on aberrant mucin glycoforms by in situ proximity ligation. J Cell Mol Med 16: 1474-1484, 2012.

13. Julien S, Videira PA and Delannoy P: Sialyl-tn in cancer: (How) Did we miss the target? Biomolecules 2: 435-466, 2012.

14. Kudelka MR, Ju T, Heimburg-Molinaro J and Cummings RD: Simple sugars to complex disease-mucin-type O-glycans in cancer. Adv Cancer Res 126: 53-135, 2015.

15. Cazet A, Julien S, Bobowski M, Burchell J and Delannoy P: Tumour-associated carbohydrate antigens in breast cancer. Breast Cancer Res 12: 204, 2010.

16. Cheever MA, Allison JP, Ferris AS, Finn OJ, Hastings BM, Hecht TT, Mellman I, Prindiville SA, Viner JL, Weiner LM and Matrisian LM: The prioritization of cancer antigens: A national cancer institute pilot project for the acceleration of translational research. Clin Cancer Res 15: 5323-5337, 2009.

17. Alos L, Lujan B, Castillo M, Nadal A, Carreras M, Caballero M, de Bolos $\mathrm{C}$ and Cardesa A: Expression of membrane-bound mucins (MUC1 and MUC4) and secreted mucins (MUC2, MUC5AC, MUC5B, MUC6 and MUC7) in mucoepidermoid carcinomas of salivary glands. Am J Surg Pathol 29: 806-813, 2005.

18. Handra-Luca A, Lamas G, Bertrand JC and Fouret P: MUC1, MUC2, MUC4, and MUC5AC expression in salivary gland mucoepidermoid carcinoma: Diagnostic and prognostic implications. Am J Surg Pathol 29: 881-889, 2005.

19. Matsuno YK, Saito T, Gotoh M, Narimatsu H and Kameyama A: Supported molecular matrix electrophoresis: A new tool for characterization of glycoproteins. Anal Chem 81: 3816-3823, 2009.

20. Kameyama A, Yamakoshi K and Watanabe A: A rapid separation and characterization of mucins from mouse submandibular glands by supported molecular matrix electrophoresis. Biochim Biophys Acta Proteins Proteom 1867: 76-81, 2019.

21. Brierley JD, Gospodarowicz $M K$ and Wittekind $C$ : TNM Classification of Malignant Tumours. 8th edition. Wiley-Blackwell, Oxford, p272, 2016.

22. Yamamoto M, Bhavanandan VP, Nakamori S and Irimura T: A novel monoclonal antibody specific for sialylated MUC1 mucin. Jpn J Cancer Res 87: 488-496, 1996.

23. Takeuchi H, Kato K, Denda-Nagai K, Hanisch FG, Clausen H and Irimura T: The epitope recognized by the unique anti-MUC1 monoclonal antibody MY.1E12 involves sialyl alpha 2-3galactosyl beta $1-3 \mathrm{~N}$-acetylgalactosaminide linked to a distinct threonine residue in the MUC1 tandem repeat. J Immunol Methods 270: 199-209, 2002

24. Matsuno YK, Dong W, Yokoyama S, Yonezawa S, Saito T, Gotoh M, Narimatsu H and Kameyama A: Improved method for immunostaining of mucin separated by supported molecular matrix electrophoresis by optimizing the matrix composition and fixation procedure. Electrophoresis 32: 1829-1836, 2011.

25. Matsuno YK, Dong W, Yokoyama S, Yonezawa S, Narimatsu H and Kameyama A: Identification of mucins by using a method involving a combination of on-membrane chemical deglycosylation and immunostaining. J Immunol Methods 394: 125-130, 2013.

26. Xu J, Sun H, Huang G, Liu G, Li Z, Yang H, Jin L, Cui X, Shi L, Ma T, et al: A fixation method for the optimisation of western blotting. Sci Rep 9: 6649, 2019

27. Ju T, Lanneau GS, Gautam T, Wang Y, Xia B, Stowell SR, Willard MT, Wang W, Xia JY, Zuna RE, et al: Human tumor antigens Tn and sialyl Tn arise from mutations in Cosmc. Cancer Res 68: 1636-1646, 2008

28. Matse JH, Bharos WK, Veerman ECI, Bloemena E and Bolscher JGM: Mucoepidermoid carcinoma-associated expression of MUC5AC, MUC5B and mucin-type carbohydrate antigen sialyl-Tn in the parotid gland. Arch Oral Biol 82: 121-126, 2017.

29. Pushpass RG, Pellicciotta N, Kelly C, Proctor G and Carpenter GH: Reduced salivary mucin binding and glycosylation in older adults influences taste in an in vitro cell model. Nutrients 11: 2280, 2019.

30. Bafna S, Kaur S and Batra SK: Membrane-bound mucins: The mechanistic basis for alterations in the growth and survival of cancer cells. Oncogene 29: 2893-2904, 2010.
31. Xu F, Liu F, Zhao H, An G and Feng G: Prognostic significance of mucin antigen MUC1 in various human epithelial cancers: A meta-analysis. Medicine (Baltimore) 94: e2286, 2015.

32. Peraza A, Gómez R, Beltran J and Amarista FJ: Mucoepidermoid carcinoma. An update and review of the literature. J Stomatol Oral Maxillofac Surg 121: 713-720, 2020.

33. Sengupta A, Valdramidou D, Huntley S, Hicks SJ, Carrington SD and Corfield AP: Distribution of MUC1 in the normal human oral cavity is localized to the ducts of minor salivary glands. Arch Oral Biol 46: 529-538, 2001.

34. Ponce-Bravo S, Ledesma-Montes C and Morales-Sánchez I: MUC-1 mucin in normal human salivary glands detected by HMFG-1 and HMFG-2 monoclonal antibodies. APMIS 116: 93-98, 2008.

35. Levitin F, Stern O, Weiss M, Gil-Henn C, Ziv R, Prokocimer Z, Smorodinsky NI, Rubinstein DB and Wreschner DH: The MUC1 SEA module is a self-cleaving domain. J Biol Chem 280: 33374-33386, 2005.

36. Duraisamy S, Kufe T, Ramasamy S and Kufe D: Evolution of the human MUC1 oncoprotein. Int J Oncol 31: 671-677, 2007.

37. Ma S, An F, Li LH, Lin YY and Wang J: Expression of Mucin 1 in salivary gland tumors and its correlation with clinicopathological factors. J Biol Regul Homeost Agents 33: 563-569, 2019.

38. Kusafuka K, Itoh H, Sugiyama C and Nakajima T: Low-grade salivary duct carcinoma of the parotid gland: Report of a case with immunohistochemical analysis. Med Mol Morphol 43: 178-184, 2010.

39. Cros J, Sbidian E, Hans S, Roussel H, Scotte F, Tartour E, Brasnu D, Laurent-Puig P, Bruneval P, Blons $\mathrm{H}$ and Badoual C: Expression and mutational status of treatment-relevant targets and key oncogenes in 123 malignant salivary gland tumours. Ann Oncol 24: 2624-2629, 2013.

40. Khurram SA, Sultan-Khan J, Atkey N and Speight PM: Cytogenetic and immunohistochemical characterization of mammary analogue secretory carcinoma of salivary glands. Oral Surg Oral Med Oral Pathol Oral Radiol 122: 731-742, 2016.

41. St Hill CA, Farooqui M, Mitcheltree G, Gulbahce HE, Jessurun J, Cao Q and Walcheck B: The high affinity selectin glycan ligand C2-O-sLex and mRNA transcripts of the core 2 beta-1,6-N-acetylglucosaminyltransferase (C2GnT1) gene are highly expressed in human colorectal adenocarcinomas. BMC Cancer 9: 79, 2009.

42. Machida E, Nakayama J, Amano J and Fukuda M: Clinicopathological significance of core 2 beta1,6-N-acetylglucosaminyltransferase messenger RNA expressed in the pulmonary adenocarcinoma determined by in situ hybridization. Cancer Res 61: 2226-2231, 2001.

43. Chen Z, Gulzar ZG, St Hill CA, Walcheck B and Brooks JD: Increased expression of GCNT1 is associated with altered O-glycosylation of PSA, PAP, and MUC1 in human prostate cancers. Prostate 74: 1059-1067, 2014.

44. Tsuboi S, Sutoh M, Hatakeyama S, Hiraoka N, Habuchi T, Horikawa Y, Hashimoto Y, Yoneyama T, Mori K, Koie T, et al: A novel strategy for evasion of NK cell immunity by tumours expressing core2 O-glycans. EMBO J 30: 3173-3185, 2011.

45. Basu S, Basu M and Basu SS: Biological specificity of sialyltransferases. In: Biology of the sialic acids. Rosenberg A (ed). Plenum Press, New York, pp69-94, 1995.

46. Vajaria BN, Patel KR, Begum R and Patel PS: Sialylation: An avenue to target cancer cells. Pathol Oncol Res 22: 443-447, 2016.

47. Kirwan A, Utratna M, O'Dwyer ME, Joshi L and Kilcoyne M: Glycosylation-based serum biomarkers for cancer diagnostics and prognostics. Biomed Res Int 2015: 490531, 2015.

48. Li X, Xu Y and Zhang L: Serum CA153 as biomarker for cancer and noncancer diseases. Prog Mol Biol Transl Sci 162: 265-276, 2019.

49. Ishikawa N, Hattori N, Yokoyama A and Kohno N: Utility of KL-6/MUC1 in the clinical management of interstitial lung diseases. Respir Investig 50: 3-13, 2012.

50. Silsirivanit A, Matsuda A, Kuno A, Tsuruno C, Uenoyama Y, Seubwai W, Angata K, Teeravirote K, Wongkham C, Araki N, et al: Multi-serum glycobiomarkers improves the diagnosis and prognostic prediction of cholangiocarcinoma. Clin Chim Acta 510: 142-149, 2020.

This work is licensed under a Creative Commons Attribution-NonCommercial-NoDerivatives 4.0 International (CC BY-NC-ND 4.0) License. 